\title{
Heritability of chronic venous disease
}

\author{
Andreas Fiebig • Petra Krusche • Andreas Wolf • \\ Michael Krawczak • Birgitt Timm - Susanna Nikolaus • \\ Norbert Frings $\cdot$ Stefan Schreiber
}

Received: 23 January 2010/Accepted: 13 March 2010/Published online: 31 March 2010

(C) The Author(s) 2010. This article is published with open access at Springerlink.com

\begin{abstract}
Varicose veins without skin changes have a prevalence of approximately $20 \%$ in Northern and Western Europe whereas advanced chronic venous insufficiency affects about $3 \%$ of the population. Genetic risk factors are thought to play an important role in the aetiology of both these chronic venous diseases (CVD). We evaluated the relative genetic and environmental impact upon CVD risk by estimating the heritability of the disease in 4,033 nuclear families, comprising 16,434 individuals from all over Germany. Upon clinical examination, patients were classified according to the CEAP guidelines as either $\mathrm{C} 2$ (simple varicose veins), C3 (oedema), C4 (skin changes without ulceration), C5 (healed ulceration), or C6 (active ulcers). The narrow-sense heritability $\left(h^{2}\right)$ of CVD equals $17.3 \%$ (standard error $2.5 \%$, likelihood ratio test $P=1.4 \times 10^{-13}$ ). The proportion of disease risk attributable to age (at ascertainment) and sex, the two main risk factors for CVD, was estimated as $10.7 \%$ (Kullback-Leibler deviance $R^{2}$ ). The heritability of CVD is high, thereby suggesting a notable
\end{abstract}

A. Fiebig $(\bowtie) \cdot$ S. Nikolaus $\cdot$ S. Schreiber

Institute for Clinical Molecular Biology,

Christian-Albrechts-University, Schittenhelmstr.

12, 24105 Kiel, Germany

e-mail: a.fiebig@ikmb.uni-kiel.de

A. Fiebig $\cdot$ M. Krawczak $\cdot$ B. Timm

Biobank 'popgen', Section Epidemiology,

Institute for Experimental Medicine,

Christian-Albrechts-University, 24105 Kiel, Germany

P. Krusche $\cdot$ N. Frings

Capio Mosel-Eifel-Clinic, 56864 Bad Bertrich, Germany

A. Wolf · M. Krawczak

Institute of Medical Informatics and Statistics,

Christian-Albrechts-University, 24105 Kiel, Germany genetic component in the aetiology of the disease. Systematic population-based searches for CVD susceptibility genes are therefore warranted.

\section{Background}

Chronic venous disease (CVD) is one of the most common disorders in Northern and Western Europe. According to the CEAP classification, CVD comprises those clinical entities that are characterized by visible venous ecstasies but which are not associated with an identifiable mechanism of venous dysfunction (Porter and Moneta 1995; Kistner et al. 1996). The clinical presentation of CVD ranges from complication-free telangiectasias or reticular veins, via varicose veins (VV) without oedema and skin changes, to venous ulceration. Varicose veins requiring medical care but lacking signs of oedema or skin changes are sometimes referred to as 'simple VV' and have been given CEAP classification $\mathrm{C} 2$. If skin changes or ulcerations occur, patients are defined as having 'chronic vein insufficiency' (CVI), classified as CEAP C3 to C6 (Ruckley et al. 2002). Defined in this way, CVD represents a summary term comprising patients with either simple VV or CVI (Eklof et al. 2004, 2009). Epidemiological studies of CVD have revealed that VV affects 16-46\% of females and $12-40 \%$ of males (Evans et al. 1999; Rabe et al. 2003; Carpentier et al. 2004). The prevalence of CVI ranges from 5 to $18 \%$ in females, and from 7 to $15 \%$ in males (Evans et al. 1999; Rabe et al. 2003; Carpentier et al. 2004).

Although CVD is relatively common, the aetiologic factors predisposing individuals to the dilatation, elongation and tortuosity of the saphenous vein and its tributaries are still poorly understood. The clinically observed thickening of the vessel wall appears to be associated with an 
increase of thick and disorganized collagen bundles (Sansilvestri-Morel et al. 2007). In addition to age, sex and obesity, family history was also found to be a major risk factor for CVD (Coon et al. 1973; Abramson et al. 1981; Brand et al. 1988; Franks et al. 1992; Sisto et al. 1995; De Backer 1997). However, family data were often inconsistent and confounded by selection bias (Meissner 2004). A CVD twin study reported $84 \%$ phenotypic concordance between monozygotic twins, compared to only 39\% between dizygotic twins (Niermann 1964). In view of these ambiguities, we set out to formally assess the heritability of CVD in a large sample of affected nuclear families from all over Germany.

\section{Materials and methods}

Between October 2005 and July 2008, a total of 2,701 index patients with CVD were recruited at the Capio Mosel-Eifel-Clinic (Capio MEC, Bad Bertrich, Germany), which is specialized in the treatment of severe forms of CVD. The ethics committee of the Kiel medical faculty and the local data protection authorities both approved the study. Written informed consent was obtained from all participants. Exclusion criteria were clinically overt debility, any signs of acute deep vein thrombosis and congenital causes of CVD. All patients suffered from severe injury of their great saphenous vein and had stayed in the clinic for at least 4 days.

A questionnaire was administered to each index patient by Capio MEC staff to obtain information on their demographic and personal characteristics (sex, date and place of birth, parental origin) as well as their medical history (medical treatment, pain, severe operations, age at CVD onset, presence of deep vein thrombosis, phlebitis). Duration of disease (in years) was calculated from these data as the difference between age at ascertainment and age at onset. A 30-ml blood sample for further genetic analysis, including candidate gene and genome wide association studies, was taken by Capio MEC staff and immediately frozen at $-20^{\circ} \mathrm{C}$. Genomic DNA was prepared from defrosted blood samples using the Invisorb Blood Giga Kit (Invitec, Berlin, Germany). All DNA samples were quality-checked on agarose gels. Patients were also interviewed about the CVD status of all living first degree relatives (parents and siblings). Family information was provided by all 2,701 index patients, which generated 4,033 nuclear families comprising 16,434 individuals for heritability analysis (Table 1 ).

All index patients were classified according to the severity, cause, site and specific abnormalities of their disease, using the CEAP classification. The CEAP classification was developed in 1994 by an international ad hoc committee of the American Venous Forum, endorsed by
Table 1 Data base for the estimation of narrow-sense heritability $h^{2}$

\begin{tabular}{lccc}
\hline CEAP grade & $\begin{array}{l}\text { No. } \\
\text { pedigrees }\end{array}$ & $\begin{array}{l}\text { No. nuclear } \\
\text { families }\end{array}$ & $\begin{array}{l}\text { No. } \\
\text { individuals }\end{array}$ \\
\hline Any (CVD) & 2,701 & 4,033 & 16,434 \\
C2 (VV) & 448 & 662 & 2,706 \\
C3 & 1,698 & 2,539 & 10,317 \\
C4 & 441 & 656 & 2,702 \\
C5\&C6 & 114 & 174 & 701 \\
C3 to C6 (CVI) & 2,253 & 3,369 & 13,720 \\
C2 to C4 & 2,587 & 3,857 & 15,725 \\
\hline
\end{tabular}

the Society for Vascular Surgery and incorporated into the 'Reporting Standards in Venous Disease' in 1995 (Porter and Moneta 1995; Kistner et al. 1996). The CEAP classification underwent its first official review and revision by an international panel under the auspices of the American Venous Forum in 2004 by Eklof et al. (2004). Its key

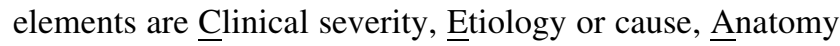
and Pathophysiology.

Clinical severity was the most important criterion for the initial assessment of index patients in our study. There are seven grades of increasing clinical severity of CVD: C0, no evidence for venous disease; $\mathrm{C} 1$, superficial spider veins; $\mathrm{C} 2$, simple VV; C3, oedema of venous origin; C4, skin changes ascribed to venous disease (e.g. pigmentation, venous eczema and lipodermatosclerosis); C5, skin changes as defined above, with healed ulceration; C6, skin changes, as defined above, with active ulceration. Groups $\mathrm{C} 5$ and $\mathrm{C} 6$ were combined in our study ('C5\&C6') because of the limited number $(n=114)$ of samples available (Table 1). Patients of grades C3 to C6 show an increasing severity of CVI, and all suffer from a functional abnormality of the venous system. For estimating heritability (Fisher 1918) CVD status ('affected', 'non-affected'), current age and sex were recorded for all first degree relatives. It should be noted that, so far, only a few prevalence studies have used the CEAP classification as a phenotypic measure (Rabe et al. 2003; Carpentier et al. 2004).

Preoperative diagnostic tests entering into the CEAP grading of index patients included handheld Doppler evaluation of the great and small saphenous veins as well as venous duplex ultrasonography. In combining B mode imaging with pulsed Doppler, duplex is capable of accurately localizing both the venous obstruction and the valvular reflux to specify venous segments. Colour duplex imaging was performed with a Hewlett Packard Image Point HX, employing a 7.5 MHz probe. Examinations were undertaken with the patient in a standing position, using the valsalva manoeuvre and manual calf compression. A reflux $>2$ s was considered clinically significant. For estimating the actual length of clinically significant reflux, the handheld Doppler and the colour duplex imagine were 
combined with photoplethysmography to gauge the venous hemodynamics. Repeating the test while firmly compressing a particular vein allows assessment of the degree of hemodynamic disturbance contributed by that vein. Specifically, if the venous refilling time increases from $10 \mathrm{~s}$ (15) to $>25 \mathrm{~s}$ when the vein is compressed, this vein can be assumed to contribute sizeably to the patients health problem (Meissner 2004).

The genetic contribution to CVD was assessed by estimating the heritability of the disease using a pedigreebased likelihood approach as implemented in the SOLAR software package (Almasy and Blangero 1998). A total of 2,701 pedigrees comprising the index patient and the selfreported disease status of their first degree relatives (parents and siblings) were used for analysis. The narrow-sense heritability, $h^{2}$, is defined as the proportion $V_{\mathrm{A}}$ of the phenotypic variance $V_{\mathrm{P}}$ in a population that is attributable to additive genetic causes, i.e., $h^{2}=V_{\mathrm{A}} / V_{\mathrm{P}}$ (Visscher et al. 2008). A $95 \%$ confidence interval for $h^{2}$ was derived as \pm 2 standard errors of the estimate. The statistical significance of $h^{2}$ was assessed by means of a likelihood ratio test (Guerra et al. 1999). The influence of the two main CVD risk factors, namely sex and age, upon CEAP grade was estimated using the Kullback-Leibler deviance $R^{2}$. The $h^{2}$ values of individual CEAP grades or grade ranges (Tables 1,2) were estimated grouping index patients into six subgroups, namely $\mathrm{C} 2, \mathrm{C} 3, \mathrm{C} 4, \mathrm{C} 5 \& \mathrm{C} 6, \mathrm{C} 3$ to $\mathrm{C} 6$ (CVI) and $\mathrm{C} 2$ to $\mathrm{C} 4$ (samples without any past or acute venous ulcer). Sex differences in terms of ascertainment age, age at CVD onset, disease duration or BMI were assessed for statistical significance using a Welch $t$ test for unpaired samples. Two-factor analysis of variance was carried out to evaluate the joint influence of sex and CEAP grades on BMI. All statistical analyses were done by using R version 2.8.1 (http://www.R-project.org).

\section{Results}

We recruited 2,701 patients (1,904 females, 797 males), which represented approximately $90 \%$ of the total number of patients treated at Capio MEC between October 2005 and July 2008 (Table 3). Simple VV (CEAP grade C2) was diagnosed in $448(16.6 \%)$ of the patients $(13.0 \%$ of males, $18.1 \%$ of females). In total, $2,253(83.4 \%)$ of the index patients were affected by CVI (CEAP grade C3 to C6), the majority having either grade $\mathrm{C} 3(62.8 \%)$ or grade $\mathrm{C} 4$ $(16.3 \%)$. Only $4.2 \%$ were affected by grades C5 and C6 (Table 3). Males were more severely affected (C4 27.4\%, C5\&C6 5.5\%) than females (C4 11.7\%, C5\&C6 3.7\%). Heritability estimation was carried out in 4,033 nuclear families from 2,701 pedigrees, comprising a total of 16,434 individuals (Table 1), with family sizes varying between 3 and 14 individuals. The $h^{2}$ estimate for overall CVD was $17.3 \pm 2.5 \%\left(P=1.4 \times 10^{-13} ;\right.$ Table 2$)$. For grade $\mathrm{C} 2$ alone, $h^{2}$ was $18.5 \pm 6.0 \%\left(P=7.3 \times 10^{-4}\right)$ whereas $h^{2}$ equalled $17.1 \pm 2.2 \%\left(P=2.0 \times 10^{-49}\right)$ for the CVI phenotype (grades $\mathrm{C} 3$ to $\mathrm{C} 6)$. The grade-specific estimates of $h^{2}$ were as follows: $9.2 \pm 11.3 \%$ for C5\&C6 $(P=0.192$, not significant), $18.3 \pm 2.1 \%$ for $\mathrm{C} 3\left(P=1.5 \times 10^{-9}\right)$ and $16.7 \pm 6.0 \%$ for $\mathrm{C} 4\left(P=1.2 \times 10^{-3}\right)$. Using age (at blood donation) and sex as covariates, the Kullback-Leibler deviance $R^{2}$ was estimated to be $10.7 \%\left(P=4.6 \times 10^{-9}\right)$. A notably smaller Kullback-Leibler $R^{2}$ was only observed for C5\&C6 grades $(3.5 \%)$.

The mean ascertainment age of our patients was 56.2 years [standard deviation (SD) 11.1 years, range 1883 years; Table 4]. No significant age difference was observed between the two sexes. The overall mean age at CVD onset was 32.6 years (SD 12.2, range 5-72), with 36.8 years (SD 12.8, range 5-72) for males and 30.8 years (SD 11.3, range 6-72) for females (Table 4). The gradespecific mean age of onset ranged from 30.7 years (SD 10.8) for C5\&C6 to 35.8 years (SD 11.6) for C2 whereas the grade-specific mean age at ascertainment of our patients ranged from 52.0 years (SD 12.3) for $\mathrm{C} 2$ to 60.9 years (SD 10.4) for C5\&C6 (Table 5). The mean disease duration was 23.4 years (SD 12.9, range 0-63) for all index patients combined, 19.3 years (SD 12.7, range 0 55) for males, and 25.1 years (SD 12.9, range 0-63) for females (Table 4). The grade-specific mean of the disease duration ranged from 20.1 years (SD 12.8 years) for grade
Table 2 Estimates of the narrow-sense heritability $\left(h^{2}\right)$ for different CEAP grades $h^{2}=0$, adjusted for age and sex

\begin{tabular}{lcccc}
\hline CEAP grade & $h^{2}(\%)$ & $\begin{array}{l}\text { Standard } \\
\text { error }(\%)\end{array}$ & $P$ value $^{\mathrm{a}}$ & $\begin{array}{c}\text { Kullback-Leibler } \\
\text { Deviance } R^{2}(\%)\end{array}$ \\
\hline Any (CVD) & 17.3 & 2.5 & $1.4 \times 10^{-13}$ & 10.7 \\
C2 (VV) & 18.5 & 6.0 & $7.3 \times 10^{-4}$ & 12.2 \\
C3 & 18.3 & 2.1 & $1.5 \times 10^{-9}$ & 11.8 \\
C4 & 16.7 & 6.0 & $1.2 \times 10^{-3}$ & 8.5 \\
C5\&C6 & 9.2 & 11.3 & 0.192 & 3.5 \\
C3 to C6 (CVI) & 17.1 & 2.2 & $2.0 \times 10^{-49}$ & 10.4 \\
C2 to C4 & 17.6 & 2.3 & $2.2 \times 10^{-13}$ & 11.0 \\
\hline
\end{tabular}


Table 3 Prevalence of different CEAP grades in the study population venous insufficiency

\begin{tabular}{llll}
\hline CEAP grade & $\begin{array}{l}\text { Total } \\
(n=2,701)\end{array}$ & $\begin{array}{l}\text { Males } \\
(n=797,29.5 \%)\end{array}$ & $\begin{array}{l}\text { Females } \\
(n=1,904,70.5 \%)\end{array}$ \\
\hline C2 $(\mathrm{VV})$ & $448(16.6 \%)$ & $104(13 \%)$ & $344(18.1 \%)$ \\
C3 & $1,698(62.8 \%)$ & $431(54.1 \%)$ & $1,267(66.5 \%)$ \\
C4 & $441(16.3 \%)$ & $218(27.4 \%)$ & $223(11.7 \%)$ \\
C5\&C6 & $114(4.2 \%)$ & $44(5.5 \%)$ & $70(3.7)$ \\
C3 to C6 $(\mathrm{CVI})$ & $2,253(83.4 \%)$ & $693(87 \%)$ & $1,560(81.9)$ \\
C2 to C4 & $2,587(95.7 \%)$ & $753(94.5 \%)$ & $1,834(96.3 \%)$ \\
\hline
\end{tabular}

Table 4 Characteristics of CVD patients

\begin{tabular}{|c|c|c|c|c|c|c|c|}
\hline & $\begin{array}{l}\text { All patients } \\
(n=2,701)\end{array}$ & $\begin{array}{l}\text { SD } \\
\text { (range) }\end{array}$ & $\begin{array}{l}\text { Males } \\
(n=797)\end{array}$ & $\begin{array}{l}\text { SD } \\
\text { (range) }\end{array}$ & $\begin{array}{l}\text { Females } \\
(n=1,904)\end{array}$ & $\begin{array}{l}\text { SD } \\
\text { (range) }\end{array}$ & $P$ value \\
\hline $\begin{array}{l}\text { Age at } \\
\text { ascertainment }\end{array}$ & 56.2 years & 11.1 years $(18-83)$ & 56.2 years & 11.6 years $(18-81)$ & 56.1 years & 11.9 years $(21-83)$ & $\begin{array}{l}0.95 \\
\quad \text { (not significant) }\end{array}$ \\
\hline Age at onset & 32.6 years & 12.2 years $(5-72)$ & 36.8 years & 12.8 years $(6-72)$ & 30.8 years & 11.3 years $(5-72)$ & $2.2 \times 10^{-16}$ \\
\hline Disease age & 23.4 & 12.9 years $(0-63)$ & 19.3 years & 12.7 years $(0-55)$ & 25.1 years & 12.9 years $(0-63)$ & $2.2 \times 10^{-16}$ \\
\hline BMI & 26.8 & $4.7(14-66)$ & 27.5 & $3.7(20-53)$ & 26.6 & $5.0(14-66)$ & $9.2 \times 10^{-7}$ \\
\hline
\end{tabular}

Given are the overall and sex-specific means, standard deviations (SD) and ranges

Table 5 CEAP grade-specific characteristics of CVD patients

\begin{tabular}{lllll}
\hline CEAP grade & Age at onset & Age at ascertainment & Disease age & BMI \\
\hline C2 (VV) & $35.8(11.6,5-72)$ & $52.0(12.3,18-82)$ & $20.1(12.8,0-54)$ & $25.6(4.5,20-42)$ \\
C3 & $32.9(12.1,6-72)$ & $56.4(10.6,23-82)$ & $23.4(12.6,0-63)$ & $26.5(4.5,14-66)$ \\
C4 & $33.2(12.7,10-72)$ & $58.3(10.5,24-81)$ & $25.3(13.0,1-56)$ & $28.3(4.8,18-46)$ \\
C5\&C6 & $30.7(10.8,14-71)$ & $60.9(10.4,33-83)$ & $29.8(13.0,6-61)$ & $29.6(5.2,21-45)$ \\
C3 to C6 (CVI) & $32.8(12,6-72)$ & $57(10.6,23-83)$ & $24.1(12.8,0-63)$ & $27.1(4.7,14-66)$ \\
C2 to C4 & $32.8(12.1,5-72)$ & $55.9(11.1,18-82)$ & $23.2(12.8,0-63)$ & $26.7(4.6,14-66)$ \\
\hline
\end{tabular}

Given are the means and, in brackets, standard deviations and ranges

C2 to 29.8 years (SD 13.0 years) for grade C5\&C6 (Table 5). The mean BMI was 26.8 (SD 4.7, range 14-66) for all index patients combined, and equalled 27.5 (SD 3.7, range 20-53) for males and 26.6 (SD 5.0, range 14-66) for females (Table 4). The grade-specific BMI ranged from 25.6 (SD 4.5) for $\mathrm{C} 2$ to 29.6 (SD 5.2) for C5\&C6 (Table 5).

\section{Discussion}

The major aim of the present study was to determine the heritability of CVD and to assess the relative impact of genetic (familial background, sex) and non-genetic factors (age, BMI) upon CVD risk. Data from a large number of individual index patients and the disease status, age and sex of their first degree relatives led us to conclude that the additive genetic component of CVD is approximately $17 \%$.

Two recently published, population-based studies of CVD also used the CEAP classification to define the disease phenotype (Rabe et al. 2003; Carpentier et al. 2004). However, these studies employed a substantially different recruitment scheme than ours. The Bonn Vein Study for example, included all CEAP grades thereby addressing a much lower proportion of severe CVI cases than we did (Rabe et al. 2003). In line with the Bonn Vein Study (Rabe et al. 2003), however, males in our study were found to be more often affected by the severe CEAP grades C4 to C6 phenotypes than females.

Interestingly, $h^{2}$ was found to vary only little with disease severity (from $18.5 \%$ for $\mathrm{C} 2$ to $16.7 \%$ for $\mathrm{C} 4$; Table 5). Although not formally statistically significant $(P=0.192$, Table 2$)$, the substantially lower $h^{2}$ estimate obtained for grades C5\&C6 (9.2\%) may indicate a smaller genetic impact upon the severe CVD phenotype, since the number of samples in this category was comparatively small $(n=114)$, however, small $h^{2}$ estimate obtained may also reflect higher sampling variance. Therefore, further studies specifically targeted at severe grades C5\&C6 appear warranted. 
The main CVD risk factors identified so far have been age (at ascertainment), female sex and familial history (Rabe et al. 2003), and our study was the first to include age at disease onset and the disease duration disease as well. Index patients with simple VV (C2) were ascertained at a mean age of 52 years whereas those with a more severe form of CVI were ascertained at a mean age of 60.9 years. These results corroborate an earlier multicenter study by Carpentier (2004), which also revealed a statistically significant association between a higher CEAP grade and an older current age of patients. However, an inverse relationship was observed in our study between disease severity and the age at disease onset. Patients affected by simple VV (C2) were first affected at 35.8 years compared to 30.7 years for patients with CVI (C3 to C5\&C6). This discrepancy may be explicable in terms of the CVI phenotype requiring a longer time period for its etiopathology than VV. Indeed, CVD is a progressive disease where those with longer disease duration (i.e., earlier onset and/or older current age) can be expected to show the worst phenotype. Consequently, a remarkable increase in disease duration with disease severity was observed in our study, ranging from 20.1 years for C2, via 23.4 years and 25.3 years for C3 and C4, respectively, to 29.8 years for C5\&C6.

In most studies undertaken so far, CVD has been found to be more prevalent among women than among men (Rabe et al. 2003), although this difference was only small in a recent study by Labropoulos (2003). Among our samples, twice as many patients were female $(n=1,904$, $70.5 \%$ ) than male ( $n=797,29.5 \%)$ thereby highlighting the CVD-predisposing role of the female sex (Table 3). The reasons for the observed sex difference may be manifold. Clearly, women are more likely to seek medical attention for varicose veins and are about three times more likely to undergo treatment (Madar et al. 1986). However, a remarkable sex difference was also observed in our data in terms of the mean age at disease onset, with females showing first symptoms of CVD at 30.8 years of age, compared to 36.8 years for males (Table 4), and in terms of disease duration (19.3 years for males, 25.1 years for females). The higher proportion of female CVD patients consistently noted in previous reports, may thus be at least partially explicable by a different timing of disease in the two sexes.

Obesity has been noted to be an additional risk factor for CVD (De Backer 1997; Fowkes et al. 1999). Indeed, the mean BMI of the index patients in our study was 26.8 (Table 4). Many studies considered BMI to be more important in females than in males (De Backer 1997; Fowkes et al. 1999). In our study, however, only a small yet significant difference $\left(P=9.2 \times 10^{-7}\right)$ difference was observed between the mean BMI of males (27.5, SD 3.7) and females (26.6, SD 5.0; Table 4). However, obesity seems to play a more important role for the development of severe forms of CVD (26.5 for C3, via 28.3 for C4, to 29.6 for C5\&C6; Table 5). Indeed, in a two-factor analysis of variance, sex and CEAP grade both had a significant effect upon BMI $\left(P=7.8 \times 10^{-6}\right.$ and $\left.P=2.2 \times 10^{-16}\right)$.

Two major strengths of our study have been (1) the use of a high-risk population, thereby resulting in a higher prevalence of both simple VV and CVI than, for example, the Bonn Vein Study (Rabe et al. 2003), and (2) a large number of nuclear families available for heritability analysis. Unfortunately, all data other than those on index patients were self-reported. However, we do not regard this as a major source of upward bias for our heritability estimates because, if anything, a less than perfect patient recall will have introduced additional variance into the analysis, thereby leading to an underestimate of the true level of familiarity of CVD. Another possible drawback may have been that, by definition, $h^{2}$ is population-dependent, i.e. $h^{2}$, estimates from one population do not necessarily reflect the heritability of the same trait in another population (Visscher et al. 2008). Therefore, future studies are required to clarify whether our heritability estimate is indeed representative of CVD in general. These limitations notwithstanding, our results strongly encourage efforts to identify susceptibility genes predisposing for severe forms of CVD.

Acknowledgments We thank all the patients for their participation in this study. This work was supported in part by Capio. Patient recruitment was supported by the popgen biobank. AF, PK, AW and BT had full access to all of the data in the study and take responsibility for the integrity of the data and the accuracy of the data analysis. All authors contributed to the literature search, data interpretation and writing. AF, PK, MK, BT, SN, NF and SW contributed to the study design. AF, PK, BT and NF contributed to the collection of the data.

Open Access This article is distributed under the terms of the Creative Commons Attribution Noncommercial License which permits any noncommercial use, distribution, and reproduction in any medium, provided the original author(s) and source are credited.

\section{References}

Abramson JH, Hopp C, Epstein LM (1981) The epidemiology of varicose veins. A survey in western Jerusalem. J Epidemiol Community Health 35:213-217

Almasy L, Blangero J (1998) Multipoint quantitative-trait linkage analysis in general pedigrees. Am J Hum Genet 62:1198-1211

Brand FN, Dannenberg AL, Abbott RD, Kannel WB (1988) The epidemiology of varicose veins: the Framingham Study. Am J Prev Med 4:96-101

Carpentier PH, Cornu-Thenard A, Uhl JF, Partsch H, Antignani PL (2003) Appraisal of the information content of the C classes of CEAP clinical classification of chronic venous disorders: a multicenter evaluation of 872 patients. J Vasc Surg 37:827-833

Carpentier PH, Maricq HR, Biro C, Ponçot-Makinen CO, Franco A (2004) Prevalence, risk factors, and clinical patterns of chronic 
venous disorders of lower limbs: a population-based study in France. J Vasc Surg 40(4):650-659

Coon WW, Willis PW 3rd, Keller JB (1973) Venous thromboembolism and other venous disease in the Tecumseh community health study. Circulation 48:839-846

De Backer G (1997) Epidemiology of chronic venous insufficiency. Angiology 48:569-576

Eklof B, Rutherford RB, Bergan JJ, Carpentier PH, Gloviczki P, Kistner RL, Meissner MH, Moneta GL, Myers K, Padberg FT, Perrin M, Ruckley CV, Smith PC, Wakefield TW (2004) Revision of the CEAP classification for chronic venous disorders: consensus statement. J Vasc Surg 40:1248-1252

Eklof B, Perrin M, Delis KT, Rutherford RB, Gloviczki P (2009) Updated terminology of chronic venous disorders: the VEINTERM transatlantic interdisciplinary consensus document. J Vasc Surg 49:498-501

Evans CJ, Fowkes FG, Ruckley CV, Lee AJ (1999) Prevalence of varicose veins and chronic venous insufficiency in men and women in the general population: Edinburgh Vein Study. J Epidemiol Community Health 53:149-153

Fisher R (1918) The correlation between relatives on the supposition of Mendelian inheritance. Trans Roy Soc Edin 52:399-433

Fowkes FG, Evans CJ, Lee AJ (1999) Prevalence and risk factors of chronic venous insufficiency. Angiology 52:5-15

Franks PJ, Wright DD, Fletcher AE, Moffatt CJ (1992) A questionnaire to assess risk factors, quality of life, and use of health resources in patients with venous disease. Eur J Surg 158:149-155

Guerra R, Wan Y, Jia A, Amos CI, Cohen JC (1999) Testing for linkage under robust genetic models. Hum Hered 49:146-153

Kistner RL, Eklof B, Masuda EM (1996) Diagnosis of chronic venous disease of the lower extremities: the "CEAP" classification. Mayo Clin Proc 71:338-345

Labropoulos N (2003) Hemodynamic changes according to the CEAP classification. Phlebolymphology 40:130-136
Madar G, Widmer LK, Zemp E, Maggs M (1986) Varicose veins and chronic venous insufficiency disorder or disease? A critical epidemiological review. Vasa 15:126-134

Meissner MH (2004) Pathophysiology of varicose veins and chronic venous insufficiency. In: Hallett JW, Mills JL, Earnshaw JJ, Reekers JA (eds) Comprehensive: vascular and endovascular surgery, chap 39, sect 10. Mosby, Edinburgh, 571-589, ISBN: 0723432325

Niermann H (1964) Eine Studie über den Erblichkeitsgrad bei 89 Hautkrankheiten nach Untersuchung von 370 Zwillingspaaren. Springer, NY

Porter JM, Moneta MG (1995) Reporting standards in venous disease: an update. International Consensus Committee on Chronic Venous Disease. J Vasc Surg 21:635-645

Ruckley CV, Evans CJ, Allan PL, Lee AJ, Fowkes FG (2002) Chronic venous insufficiency: clinical and duplex correlations. The Edinburgh Vein Study of venous disorders in the general population. J Vasc Surg 36:520-525

Rabe E, Pannier-Fischer F, Bromen K, Schuldt K, Stang A, Poncar C, Wittehorst M, Bock E, Weber S, Jöckel K-H (2003) Bonner Venenstudie der Gesellschaft für Phlebologie. Phlebologie 32:114

Sansilvestri-Morel P, Fioretti F, Rupin A, Senni K, Fabiani JN, Godeau G, Verbeuren TJ (2007) Comparison of extracellular matrix in skin and saphenous veins from patients with varicose veins: does the skin reflect venous matrix changes? Clin Sci (Lond) 112:229-239

Sisto T, Reunanen A, Laurikka J, Impivaara O, Heliovaara M, Knekt P, Aromaa A (1995) Prevalence and risk factors of varicose veins in lower extremities: mini-Finland health survey. Eur $\mathrm{J}$ Surg 161:405-414

Visscher PM, Hill WG, Wray NR (2008) Heritability in the genomics era-concepts and misconceptions. Nat Rev Genet 9:255-266 